\title{
Effect of fat volume on postoperative complications and survival rate after D2 dissection for gastric cancer
}

\author{
Satoshi Inagawa, Shinya Adachi, Tatsuya Oda, Toru Kawamoto, Naoto Koike, and Katashi Fukao \\ Department of Surgery, Institute of Clinical Medicine, University of Tsukuba, 1-1-1, Tsukuba, Ibaraki 305-8575, Japan
}

\begin{abstract}
Background. D2 lymph node dissection in gastric cancer is controversial in Western countries because of the relatively high complication and mortality rates. The purpose of this study was to clarify the effects of fat volume on operation factors, postoperative complications, and survival in gastric cancer surgery.

Methods. We studied 293 consecutive patients who had undergone distal gastrectomy with $\mathrm{D} 2$ dissection for gastric cancer at our hospital between 1990 and 1997 . The patients were classified into three groups according to their body mass index $\left(B M I ; \mathrm{kg} / \mathrm{m}^{2}\right)$. We analyzed differences in the operation time, the amount of blood loss, the postoperative complications and the survival rate among the three groups.

Results. Group A patients had a BMI of less than $20(n=61)$, group B had a BMI of 20-25 $(n=178)$, and group $C$ had a BMI of more than $25(n=54)$. There were significant differences in operation time (group A, $206 \pm 66 \mathrm{~min}$; group B, 226 $\pm 61 \mathrm{~min}$; group $C, 252 \pm 61 \mathrm{~min} ; P<0.05$ ), blood loss (group $A, 417 \pm 282 \mathrm{ml}$; group $B, 501 \pm 295 \mathrm{ml}$; group $C, 605 \pm$ $333 \mathrm{ml} ; \boldsymbol{P}<\mathbf{0 . 0 5}$ ), and postoperative complications (group $\mathrm{A}$, $3.3 \%$; group $B, 5.6 \%$; group $C, 22.0 \%$ ). There were significant differences in postoperative complications between groups $\mathbf{A}$ and $C$, and between groups $B$ and $C$. However, the difference between groups $A$ and $B$ was not significant, and no significant difference in survival rate was seen among the three groups. Conclusion. Fat volume definitely increases the postoperative complications. Accordingly, the high rate of postoperative complications of $\mathrm{D} 2$ surgery in Western countries may be related to the patients' relative obesity.
\end{abstract}

Key words Gastric cancer · Lymph node dissection · Body mass index $(\mathrm{BMI}) \cdot$ Postoperative complication

Offprint requests to: $\mathrm{S}$. Adachi

Received: September 1, 2000 / Accepted: October 23, 2000

\section{Introduction}

In Japan, systemic D2 lymph node dissection (D2) is a standard, common treatment for gastric cancer. In contrast, in Western countries, the D2 procedure is thought to be too extensive. It is difficult to compare D2 and D1 dissections by randomization, because D2 dissection has already been accepted as the standard procedure in Japan. However, D2 dissection has not been accepted as standard in the West, because randomized trials in these countries have shown that it results in a higher complication rate, higher mortality rate, and longer hospital stay than the D1 procedure [1-4].

We hypothesized that this high incidence of postoperative complications might be related to the relatively larger fat volume in Western patients. There have been no reports as to this point, and we set out to clarify the effects of fat volume on the operation time, blood loss, postoperative complications, and survival rate in gastric cancer patients.

\section{Patients and methods}

We studied 293 consecutive patients who had undergone curative distal gastrectomy with D2 dissection for gastric cancer at our hospital between 1990 and 1997. The patients were assigned to three groups according to their body mass index (BMI; $\mathrm{kg} / \mathrm{m}^{2}$ ): group A, BMI less than 20; group B, BMI, 20-25; and group C, BMI more than 25 (Table 1). We compared the operation time, amount of blood loss, postoperative complications (leakage, abdominal abscess, bleeding) and survival rate among the three groups.

Using criteria defined by the Japanese Research Society for Gastric Cancer [5], we performed D2 lymph node dissection, and pathologic staging was carried out. Curative resection was defined as no residual tumor microscopically. 
Table 1. Background of the patients

\begin{tabular}{lcccc}
\hline & $\begin{array}{c}\text { Group A } \\
(n=61)\end{array}$ & $\begin{array}{c}\text { Group B } \\
(n=178)\end{array}$ & $\begin{array}{c}\text { Group C } \\
(n=54)\end{array}$ & $P$ value \\
\hline Age (years; mean) & 62.4 years & $\begin{array}{c}59.4 \text { years } \\
\text { Sex (male:female) }\end{array}$ & $\begin{array}{c}58.7 \text { years } \\
34: 20\end{array}$ & NS \\
BMI (kg/m $\mathrm{m}^{2}$ (mean $\left.\pm \mathrm{SD}\right)$ & $18.5 \pm 1.2$ & $22.6 \pm 1.62$ & $26.9 \pm 1.7$ & $<0.05$ \\
Stage & 32 & 119 & 39 & NS \\
I A & 8 & 21 & 7 & \\
I B & 9 & 23 & 5 & \\
II & 4 & 7 & 0 & \\
III A & 3 & 5 & 0 & \\
III B & 5 & 3 & 3 & \\
IV & $3(5 \%)$ & $25(14 \%)$ & $14(25 \%)$ & $<0.05$ \\
Previous disease & $4(6.6 \%)$ & $12(6.7 \%)$ & $2(3.7 \%)$ & NS \\
$\quad$ Diabetes & & & \\
Cardiovascular disease & & & & \\
\hline
\end{tabular}

Classifications of stage were made according to the Japanese classification of gastric carcinoma by the Japanese Research Society for Gastric Cancer [5]

BMI, Body mass index

Table 2. Operation time and blood loss

\begin{tabular}{lllll}
\hline & $\begin{array}{c}\text { Group A } \\
(n=61)\end{array}$ & $\begin{array}{c}\text { Group B } \\
(n=178)\end{array}$ & $\begin{array}{l}\text { Group C } \\
(n=54)\end{array}$ & $P$ value \\
\hline $\begin{array}{l}\text { Operation time (min) } \\
\quad(\text { mean } \pm \text { SD) }\end{array}$ & $206 \pm 66$ & $226 \pm 61$ & $252 \pm 61$ & $<0.05$ \\
$\begin{array}{c}\text { Blood loss (ml) } \\
(\text { mean } \pm \text { SD) }\end{array}$ & $417 \pm 282$ & $501 \pm 295$ & $605 \pm 333$ & $<0.05$ \\
\hline
\end{tabular}

To evaluate their anastomotic condition, all patients underwent upper gastrointestinal graphy 7 days after the operation. To detect abdominal abscess, we used abdominal ultrasonography or computed tomography if patients were febrile.

All values are presented as means \pm SD. Statistical analysis was performed with the $\chi^{2}$ test. Survival curves were computed by the Kaplan-Meier method, and the log-rank test was used to distinguish significant differences. The level of significance was $P<0.05$.

\section{Results}

Clinical presentation and background. There were 187 men and 106 women in the study, and the male: female ratio was $1.8: 1$. The average age of the patients was 59.9 years (range, 27 to 89 years). Group A consisted of 61 patients; group B, 178 patients; and group C, 54 patients. There was no significant difference among the three groups in terms of patient background or pathologic staging. The previous diseases of these patients were investigated. The frequency of diabetes mellitus (DM) increased significantly with increases in the patients' BMI. However, the frequency of cardiovascular disease was not related to BMI (Table 1).
BMI. The mean BMI in group A was $18.5 \pm 1.2$; in group $\mathrm{B}, 22.6 \pm 1.3$; and in group C, $26.9 \pm 1.7$. The differences among the three groups were significant.

Operation time. The mean operation time was related to the BMI: group A, $206 \pm 66 \mathrm{~min}$; group B, $226 \pm 61 \mathrm{~min}$; and group $\mathrm{C}, 252 \pm 61 \mathrm{~min}$. There were significant differences among the three groups (Table 2).

Blood loss. Mean blood loss was also related to the BMI: group A, $417 \pm 282 \mathrm{ml}$; group B, $501 \pm 295 \mathrm{ml}$; and group $\mathrm{C}, 605 \pm 333 \mathrm{ml}$. There were significant differences among the three groups (Table 2).

Postoperative complications. Postoperative complications occurred in 2 patients $(3.3 \%)$ in group A, 10 patients $(5.6 \%)$ in group $\mathrm{B}$, and 12 patients $(22.2 \%)$ in group $\mathrm{C}$ (Table 3 ). There was no significant difference between groups $\mathrm{A}$ and $\mathrm{B}$, but there were significant differences between groups $\mathrm{A}$ and $\mathrm{C}$, and groups $\mathrm{B}$ and C (Table 3).

In spite of the high proportion of diabetic patients in group $\mathrm{C}$, there were no significant differences in postoperative complication rates between DM patients and non-DM patients in this group (DM 4/14, non-DM $8 / 40)$. 
Table 3. Postoperative complication rates

\begin{tabular}{llll}
\hline & $\begin{array}{l}\text { Group A } \\
(n=61)\end{array}$ & $\begin{array}{l}\text { Group B } \\
(n=178)\end{array}$ & $\begin{array}{l}\text { Group C } \\
(n=54)\end{array}$ \\
\hline $\begin{array}{l}\text { Incidence } \\
\text { Details }\end{array}$ & $3.3 \%(2 / 61)$ & $5.6 \%(10 / 178)$ & $22.2 \%(12 / 54)$ \\
$\quad$ Leakage & $1.6 \%(1 / 61)$ & $4.5 \%(8 / 178)$ & $20.3 \%(11 / 54)$ \\
Abscess & 0 & $1.1 \%(2 / 178)$ & $1.9 \%(1 / 54)$ \\
Postoperative bleeding & $1.6 \%(1 / 61)$ & 0 & 0
\end{tabular}

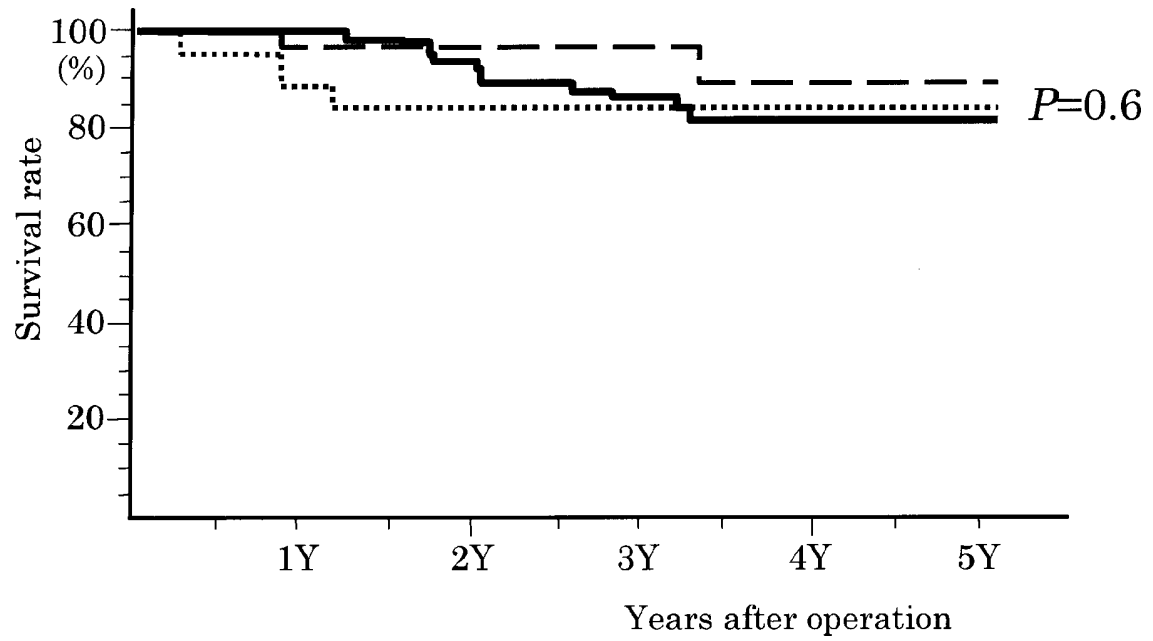

Fig. 1. Cumulative survival rate of the three groups. See text for explanation of groups. Dotted line, Group A; continuous line, Group B; dashed line, Group C
Survival rate. Survival rates were analyzed for the 233 patients who had undergone curative surgery and could be followed-up after surgery. They were followed for 0.87 to 8.94 years (mean, 4.77 years). None of the patients died within 30 days of surgery. In spite of the differences in incidence of complications, there were no significant differences in the 5-year survival rates among the three groups $(P=0.6)$ (Fig. 1).

\section{Discussion}

There has been much argument between Japan and Western countries about lymph node dissection for gastric cancer. In Japan, D2 dissection is widely used as a standard operation for gastric cancer, and extensive lymphadenectomy is performed all over the country [6]. However, in Western countries, D2 dissection is performed in fewer than $5 \%$ of patients with gastric cancer [6]. Some authors have reported that D2 dissection results in better survival rates than D1 dissection [7-9]. On the other hand, other authors have reported that D2 dissection causes an increase in postoperative complications and a longer hospital stay; these authors do not support the routine use of D2 dissection for gastric cancer $[1-4,7]$.
There are a number of differences in the characteristics of Western and Japanese patients with gastric cancer. The mean age of patients with gastric cancer is higher in Western countries than in Japan. Early gastric cancer is more frequent in Japan, and many tumors in Japanese patients are located in the distal third of the stomach [10,11].

We hypothesized that the high incidence of complications after D2 dissection in the West might be brought about by the relatively larger fat volume in the patients. We therefore evaluated the relationship between the BMI of patients and the rate of complications during and after D2 operation. The operation time, amount of blood loss, and postoperative complication rates were correlated with the BMI.

The BMI in group $\mathrm{C}$ was close to that of Western people (26.3) [12], and the postoperative complication rate in group $\mathrm{C}$ was almost the same as that found in European studies [2,7]. However, no significant difference in survival rate was seen among the three groups. Close observation, thorough treatment, and a long hospital stay may bring about a relatively low mortality rate and good survival.

Many authors have reported that, in some patients, there are $\mathrm{N} 2$ lymph node metastases of gastric carcinoma which invade to the submucosal layer [13-17]. 
The increasing use of D2 dissection in Japan has been contributing a great deal to the achievement of curative resections and a high survival rate [18]. Because frozen section diagnosis cannot be done at all institutions, D2 dissection for gastric cancer is necessary.

In recent years, the number of overweight people in Japan has increased because of changes in eating habits. Therefore, in deciding on the best surgical procedure for an individual patient, it is important that we aim to reduce the rate of postoperative complications while maintaining curability.

\section{References}

1. Cuschieri A, Fayers P, Fielding J, Ctaven J, Bancewicz J, Joypaul V, et al. Postoperative morbidity and mortality after D1 and D2 resections for gastric cancer; preliminary results of the MRC randomized controlled surgical trial. Lancet 1996;347: 995-9.

2. Bonenkamp JJ, Songun I, Hermans J, Sasako M, Welvaart K, Plukker JTM, et al. Randomized comparison of morbidity after D1 and D2 dissection for gastric cancer in 996 Dutch patients. Lancet 1995;345:745-8.

3. Dent DM, Madden MV, Price SK. Randomized comparison of R1 and R2 gastrectomy for gastric carcinoma. Br J Surg 1988; 75:110-12.

4. Bonenkamp JJ, Hermans J, Sasako M, Velde CHJ. Extended lymph-node dissection for gastric cancer. N Engl J Med 1999; 340:908-14.

5. Japanese Research Society for Gastric Cancer. The general rules for gastric cancer study (in Japanese). 13th ed. Tokyo: Kanehara; 1999.

6. Maruyama K, Okabayashi K, Kinoshita T. Progress in gastric cancer surgery in Japan and its limits of radicality. World J Surg 1987;11:418-25.
7. Siewert JR, Bottcher K, Roder JD, Busch R, Hermanek P, Meyer HJ. Prognostic relevance of systematic lymph node dissection in gastric carcinoma. Br J Surg 1993;80:1015-18.

8. Roukos DH, Lorenz M, Encke A. Evidence of survival benefit of extended (D2) lymphadenectomy in western patients with gastric cancer based on a new concept: a prospective long-term follow-up study. Surgery 1998;123:573-8.

9. Shiu MH, Moore E, Saunders M, Sanders M, Huvos A, Freedman B. Influence of the extent of resection on survival after curative treatment of gastric carcinoma. Arch Surg 1987;122:1347-51.

10. Maruyama M, Takeshita K, Endo M, Deakin M, Moossa AR. Clinicopathological study of gastric carcinoma in high- and lowmortality countries: comparison between Japan and the United States. Gastric Cancer 1998;1:64-70.

11. Wanebo HJ, Kennedy BJ, Chmiel J, Steele G Jr, Winchester D. Cancer of the stomach; a patient care study by the American College of Surgeons. Ann Surg 1993;218:583-92.

12. Heini AF, Weinsier RL. Divergent trends in obesity and fat intake patterns: the American paradox. Am J Med 1997;102:259-64.

13. Kitamura K, Yamaguchi T, Taniguchi H, Hagiwara A, Sawai K, Takahashi T. Analysis of lymph node metastasis in early gastric cancer. Rationale of limited surgery. J Surg Oncol 1997;64:42-7.

14. Yasuda K, Shiraishi N, Suematsu T, Yamaguchi K, Adachi Y, Kitano S. Rate of detection of lymph node metastasis is correlated with the depth of submucosal invasion in early stage gastric carcinoma. Cancer 1999;85:2119-23.

15. Okamura T, Tsujitani S, Korenaga D, Haraguchi M, Baba H, Hiramoto Y. Lymphadenectomy for cure in patients with early gastric cancer and lymph node metastasis. Am J Surg 1988;155: 476-80.

16. Inoue K, Tobe T, Kan N, Nio Y, Sakai M, Takeuchi E. Problems in the definition and treatment of early gastric cancer. Br J Surg 1991;78:818-21.

17. Oliveira FJ, Ferrao H, Furtado E, Batista H, Conceicao L. Early gastric cancer; report of 58 cases. Gastric Cancer 1998;1:51-6.

18. Kinoshita T, Maruayma K, Sasako M, Okajima K. Treatment results of gastric cancer patients; Japanese experience. In: Nishi M, Ichikawa H, Nakajima T, Maruyama K, Tahara E, editors. Gastric cancer. Tokyo Berlin Heidelberg New York London Paris Hong Kong Barcelona Budapest: Springer-Verlag; 1993. pp. 319-29. 